\title{
Analysis on the optimal solar multiples and full load hours of heat storage for trough high temperature molten salt concentated solar power (CSP) plant
}

\author{
Wu Wangsong,Huang Jing,Liu Xiaosong
}

(Power China Zhongnan Engineering Corporation Limited,Changsha 410014, China)

Keywords: Parabolic trough; molten salt; generated electricity; initial capital; LCOE

Abstract: Parabolic trough CSP plant operates commercially in the most mature way, also is one of mainstream technology trends for future CSP generation in China. The parabolic trough CSP plant adopting high temperature molten salt delivers higher working temperature and efficiency. The generated electricity increases with increase of solar multiples and full load hours of heat storage, which, however, also augments initial capital of power station, so the optimal solar multiples and full load hours of heat storage must be found out from generated electricity and initial capital. A Chinese demonstration CSP plant is taken for example to analyze the optimal solar multiples and full load hours so as to provide an effective method for general scheme design of trough molten salt CSP plant.

\section{Introduction}

The solar power, a kind of regenerative energy, is characterized by large reserves and wide distribution. Compared with PV generation, the solar thermal power generation has advantages of high quality of electric power and ability to store energy and regulate peak. In September 2016, the Chinese National Energy Administration promulgated Notification Concerning Constructing Demonstration CSP Projects, which lists 20 projects into the first batch of demonstration projects of CSP plant, with 7 being parabolic trough CSP plants. This paper takes a Chinese demonstration CSP plant for example to analyze the optimal solar multiples and full load hours of heat storage so as to provide an effective method for general scheme design of trough high temperature molten salt CSP plant.

\section{The trough high temperature molten salt CSP plant system}

The trough high temperature molten salt CSP plant system comprises four systems of solar field, heat storage system, steam generation system and turbine generating system. The working medium adopts mixed molten salt of $\mathrm{NaNO}_{3}, \mathrm{KNO}_{3}$ and $\mathrm{LiNO}_{3}$, whose melting point is $82^{\circ} \mathrm{C}$. The cold molten salt for solar heat collection system is led from cold tank, whose normal operation temperature is $290^{\circ} \mathrm{C}$. After heated by solar heat collection system, the cold molten salt is transferred to hot molten salt tank, whose normal operation temperature is $550^{\circ} \mathrm{C}$. The high temperature molten salt enters cold molten salt tank after heating water to produce steam of $535^{\circ} \mathrm{C}$ and 10.4MPa. The steam is cooled in the air-cooled system after working in the turbine and then enters steam generation system for circulation. The schematic of trough high temperature molten salt CSP plant is as shown in figure 1. 


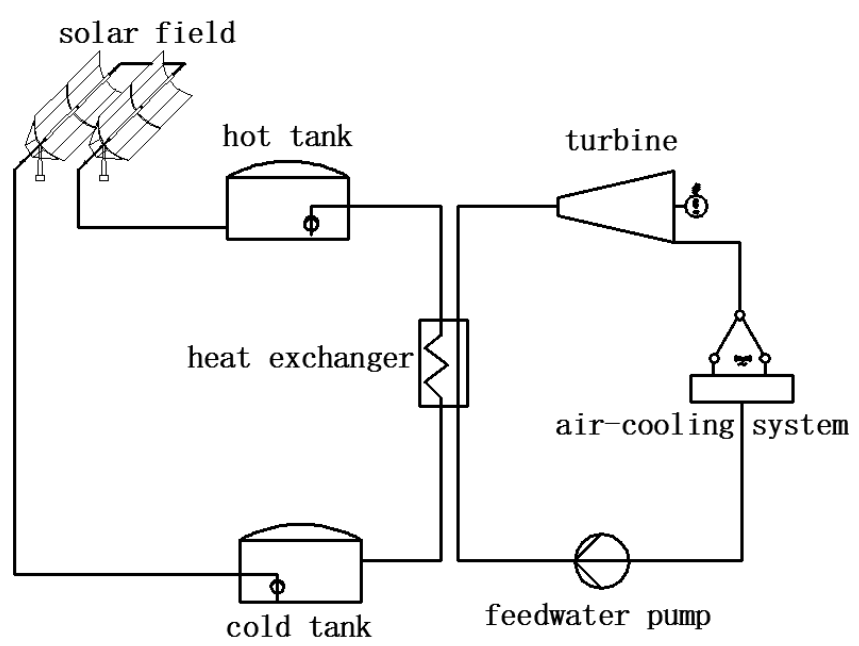

Figure 1 Schematic diagram for trough molten salt CSP plant

\section{Solar field}

Every 6 heat collectors, which are about $870 \mathrm{~m}$ in total length, constitute a loop that is connected to the header pipe at two ends of two sides. The axis of heat collector is arranged in east-west direction, and tracks the sun in south-west direction, to make the sunshine always focus on receives so as to maximally absorb the direct solar radiation energy. Aperture of each loop is up to $6,624 \mathrm{~m}^{2}$. One end of the loop is connected to the cold molten salt header pipe, while another end is connected to the hot molten salt header pipe. The molten salt in the cold tank is pumped to the cold molten salt header pipe, then the cold header pipe distribute the fluid to each loop in the solar field. The molten salt is heated in loop before flowing into the hot header pipe, where the high temperature molten salt from all loops converges to hot tank.

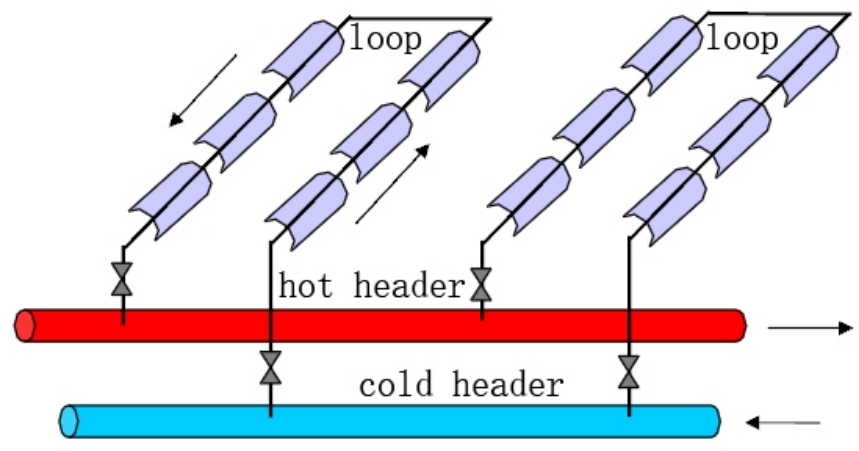

Figure 2 Sketch map for solar collector loop

\section{Thermal storage system}

The illumination is fully utilized in the light period. Except the high temperature molten salt flow needed for normal operation of plant unit, the surplus high temperature molten salt produced by heat collection field is stored in storage tank of hot molten salt for use in night or insufficient illumination period.

The hot molten salt is pumped from hot tank to superheater, reheater, steam generator, feedwater preheater and then enter cold tank.

\section{Power cycle}

The steam parameters are $535^{\circ} \mathrm{C}$ and $10.4 \mathrm{MPa}$. The rated power of steam turbine is $64 \mathrm{MW}$. In an effort to raise the thermal efficiency of ranking cycle and general efficiency of power plant, a intermediate reheating system is arranged with 4HP heaters, 1 deaerator and $3 \mathrm{LP}$ heaters. The rated efficiency of steam turbine cycle is $43 \%$. It adopts direct air-cooling system which mainly comprises: steam turbine discharging pipeline, air-cooling condenser, condensate water system, draining system and vacuum-pumping system, etc. 


\section{Calculation tool and radiation data}

\section{Calculation tool}

The project's calculation model for generated electricity is based on SAM (System Advisor Model) which is widely applied to the domain of solar power generation. The calculation model established using SAM can provide each hour electricity output of CSP plant, generate the data of each result for 8,760 hours in one year, and assess and optimize the comprehensive performance of the calculation result. SAM model includes three modules, which respectively correspond to three steps of the analysis process: firstly, set input conditions of CSP plant; secondly, calculate the model which has set input conditions; thirdly, output result, summarize and analyze The performance calculation rests with the meteorological conditions of the site, general configuration of CSP plant, configuration condition of each subsystem (such as solar heat collection field, thermal storage system, steam generator system, turbine generating system, etc.) etc.

\section{Radiation data}

The generated electricity of CSP plant is closely related the solar irradiation of the site. The total solar radiation from sunshine arriving at the earth is divided into diffused radiation and direct radiation. The CSP plant can only collect and utilize the direct solar radiation.

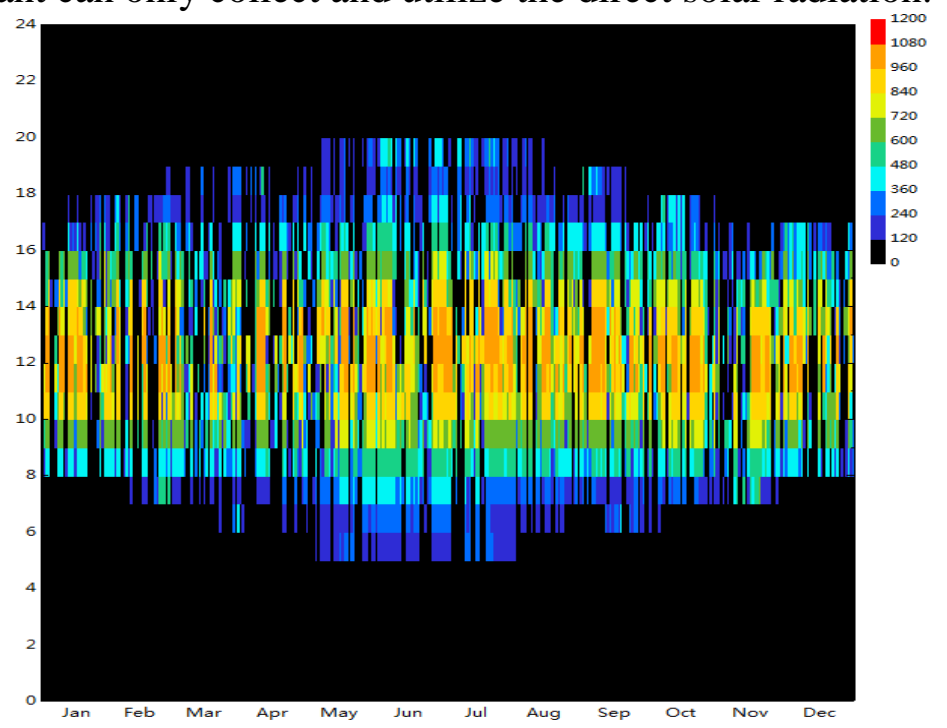

Figure 3 Hourly scatter gram for annual direct solar radiation intensity

The meteorological data documents needed by SAM calculation model include geo information of project's site (longitude, latitude, altitude, time zone the site belongs to, etc.), and weather information such as sunlight radiation intensity of 8,760 hours in one year (including horizontal radiation intensity, direct radiation intensity, scattered radiation intensity), air temperature, humidity, atmosphere and wind speed, etc. The scatter gram of annual solar radiation intensity for the project's site is as shown in figure 3, and table 1 is the converted monthly statistics.

Table 1 Average direct radiation for each month

\begin{tabular}{c|c|c|c}
\hline Month & $\begin{array}{c}\text { Direct radiation } \\
\left(\mathrm{kWh} / \mathrm{m}^{2}\right)\end{array}$ & Month & $\begin{array}{c}\text { Direct radiation } \\
\left(\mathrm{kWh} / \mathrm{m}^{2}\right)\end{array}$ \\
\hline Jan & 147.1 & Aug & 243.8 \\
\hline Feb & 126.0 & Sep & 226.5 \\
\hline Mar & 153.1 & Oct & 192.9 \\
\hline Apr & 154.9 & Nov & 135.6 \\
\hline May & 230.5 & Dec & 133.5 \\
\hline Jun & 266.5 & average & 190 \\
\hline Jul & 269.2 & total & 2279.6 \\
\hline
\end{tabular}




\section{Calculation result and analysis}

\section{Calculation result and analysis of generated electricity and efficiency of plant}

The generated electricity is an important index evaluating the CSP plant, which increases with increase of solar multiples (scale of solar field) and full load hours of heat storage. It is observed from figure 4. When fixing full load hours of heat storage is $16 \mathrm{~h}$. When solar multiples increase from 2 to 5 , i.e. the solar field aperture increases from $612,000 \mathrm{~m}^{2}$ to $1,529,000 \mathrm{~m}^{2}$, the annual generated electricity increases from $198,000,000 \mathrm{kWh}$ to $353,000,000 \mathrm{kWh}$. When the full load hours of heat storage increases from $6 \mathrm{~h}$ to $20 \mathrm{~h}$, the generated electricity begins to increase significantly, then the increase range becomes lower and lower. When the full load hours of heat storage exceeds $16 \mathrm{~h}$, the generated electricity's increase range is on the small margin.

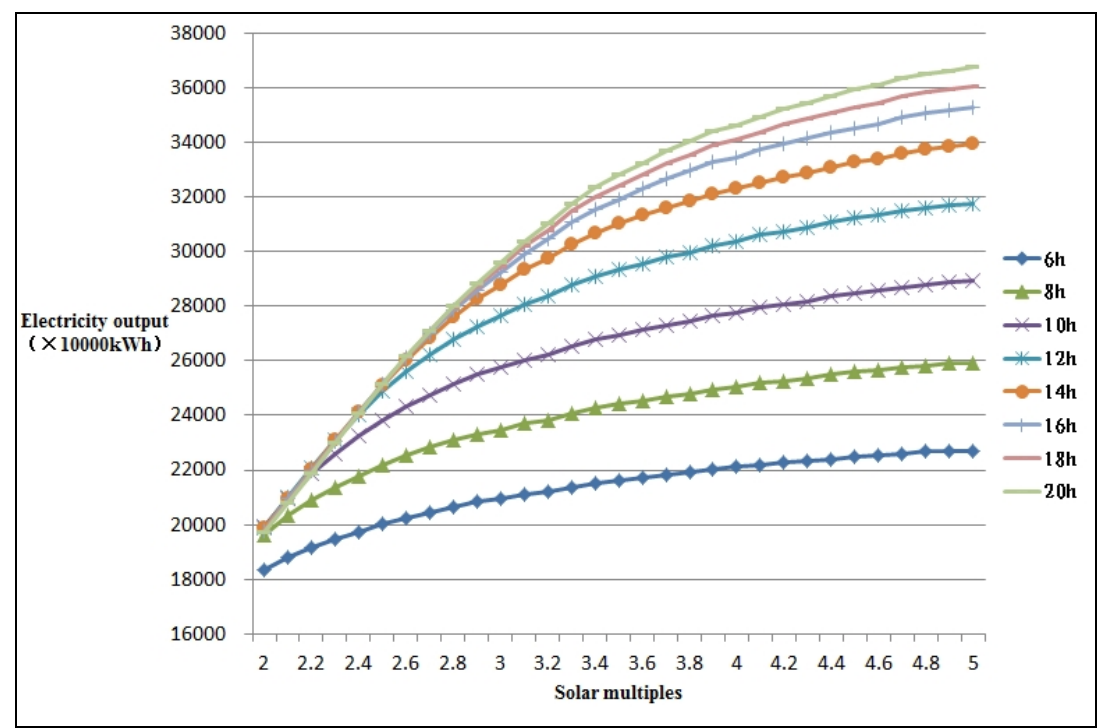

Figure 4 The change trend of generated electricity with increase of solar multiples and full load hours of heat storage

Also, according to figure 5, the fixed full load hours of heat storage is $16 \mathrm{~h}$. When solar multiples increase from 2 to 2.5 , i.e. the solar field aperture increases from $612,000 \mathrm{~m}^{2}$ to $765,000 \mathrm{~m}^{2}$, the net efficiency of CSP plant increases from $14.19 \%$ to $14.42 \%$, which is the highest value for net efficiency. With solar multiples increasing to 5 , the net efficiency decreases to $10.12 \%$. When solar multiples exceed 3 , the net efficiency of CSP plant significantly increases with increase of full load hours of heat storage, but the increase range becomes lower and lower.. When the full load hours of heat storage exceeds $16 \mathrm{~h}$, the increase range of net efficiency is small. 


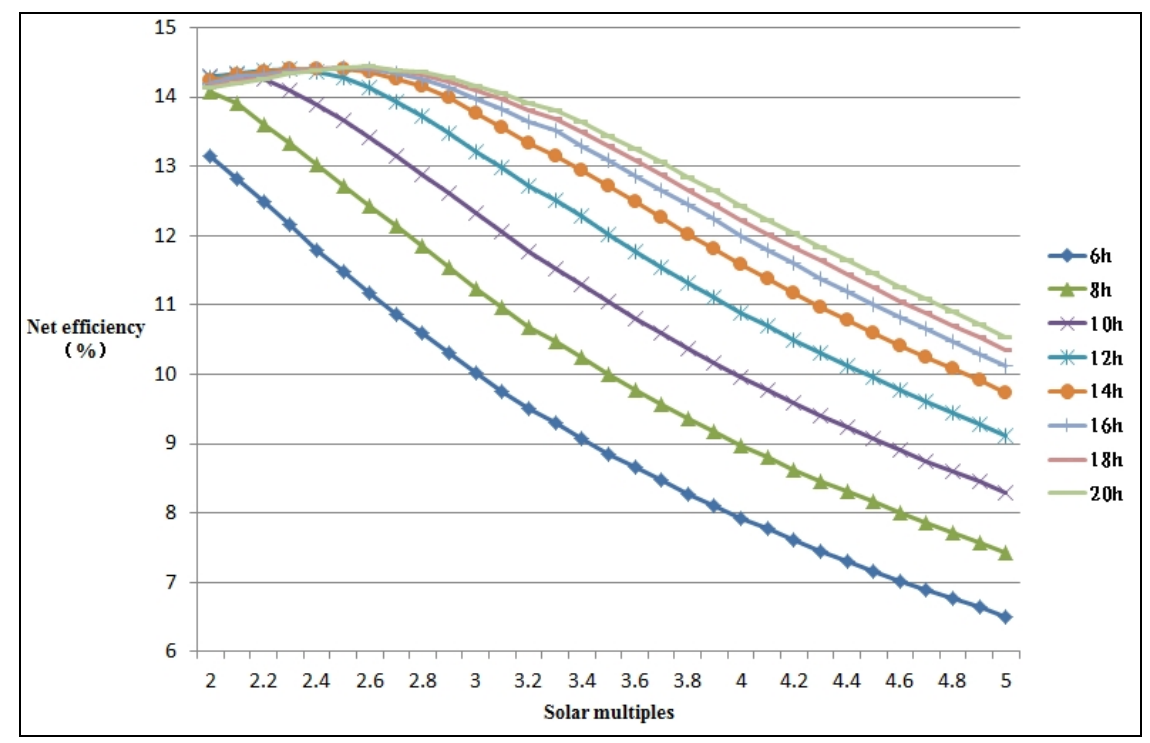

Figure 5 The change trend of net efficiency with increase of solar multiples and full load hours of heat storage

\section{Calculation result and analysis of $\mathrm{LCOE}$}

The generated electricity increases with increase of solar multiples (solar field aperture) and full load hours of heat storage, but the initial capital of power station increases too, a balance point must be find out between generated electricity and initial capital. The index to evaluate the economy of CSP plant is LCOE, which can be calculated via following equation:

$$
\mathrm{LCOE}=\frac{\text { CAPEX }+\sum_{\mathrm{t}=1}^{\mathrm{n}} \frac{\text { OPEX }_{\mathrm{t}}}{(1+\mathrm{r})^{\mathrm{t}}}}{\sum_{\mathrm{t}=1}^{\mathrm{n}} \frac{\text { Electricity Generated }_{\mathrm{t}}}{(1+\mathrm{r})^{\mathrm{t}}}}
$$

Where: $\mathrm{n}=$ life of project; $\mathrm{r}=$ discount rate; CAPEX = total initial capital of the project; OPEX $=$ total expenditure for operation and maintenance; Electricity generated = generated electricity.

According to market condition, set the package price for heat collector as $1080 \mathrm{Yuan} / \mathrm{m}^{2}$ and price of molten salt as 8000 Yuan/t, and the LCOE calculated by this is as shown in figure 6 . The fixed full load hours of heat storage is $16 \mathrm{~h}$, and when the solar multiples increase from 2 to 5 , i.e. the solar field aperture increases from $612,000 \mathrm{~m}^{2}$ to $1,529,000 \mathrm{~m}^{2}$, the LCOE first falls to touch the bottom of $0.752 \mathrm{Yuan} / \mathrm{kWh}$ before increasing again. When the solar multiples (solar field aperture) is small, the LCOE increases with increase of full load hours of heat storage; while when the solar multiples (solar field aperture) is large, the LCOE falls with increase of full load hours of heat storage. When the sun multiple is 3.4 and full load hours of heat storage is $16 \mathrm{~h}$, the LCOE is the lowest 0.752 Yuan $/ \mathrm{kWh}$.

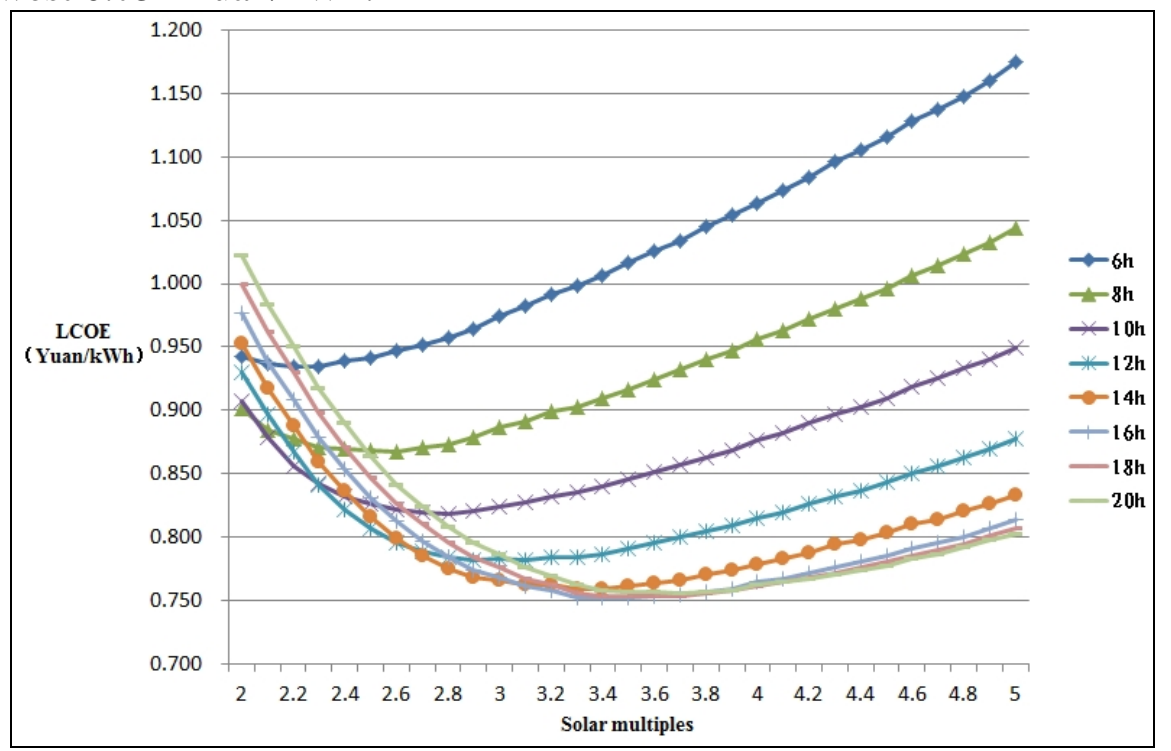

Figure 6 The change trend of LCOE with increase of solar multiples and full load hours of heat storage 


\section{Conclusion}

Following conclusions are derived from the calculation and analysis herein:

(1) The generated electricity increases with solar multiples (solar field aperture) and full load hours of heat storage. However, the generated electricity's increase range significantly reduces when the full load hours of heat storage exceeds a certain threshold.

(2) The net efficiency of CSP plant first rises to the peak value and then falls with increase of solar multiples (solar field aperture) and full load hours of heat storage. When the full load hours of heat storage exceeds a certain threshold, the net efficiency of CSP plant sees a significant reduction of increase range.

(3) The LCOE first falls to the minima and then falls with increase of solar multiples (solar field aperture) and full load hours of heat storage. When the full load hours of heat storage exceeds a certain threshold, the LCOE sees a significant reduction of decrease range.

Presently the LCOE serves as the main index evaluating the economic benefit of commercial CSP plant. The calculation and analysis herein shows that there exists the optimal solar multiples and full load hours of heat storage for solar CSP plant to reach the lowest LCOE and realize the highest economic benefit, which theory can be extensively applied to the general scheme design of commercial CSP plant.

\section{References}

[1] Tom Ferguson, Paul Gilman, and Steven Janzou. System Advisor Model General Description. National Renewable Energy Laboratory (NREL).2014.

[2] R. Forristall. Heat Transfer Analysis and Modeling of parabolic trough solar receiver. National Renewable Energy Laboratory (NREL).2003.

[3] MICHAEL J. WAGNER. Simulation and Predictive Performance Modeling of Utility-Scale Central Receiver System Power Plants. UNIVERSITY OF WISCONSIN - MADISON. 2008.

[4] Michael J. Wagner and Paul Gilman.Technical Manual for the SAM Physical Trough Model. National Renewable Energy Laboratory (NREL).2011.

[5] M. Sengupta, A. Habte, S. Kurtz et al.Best Practices Handbook for the Collection and Use of Solar Resource Data for Solar Energy Applications. National Renewable Energy Laboratory (NREL).2015.

[6] Gianluigi Angelantoni. The Molten Salt Parabolic Troughs:A New Technology for CSP in China. BIT's 4th New Energy Forum. 2014.

[7] Moh.Malik AfandiDinda Dwi Chandrarini. Optimization of Solar Energy Utilization Using Concentrated Solar Hybrid Energy Harvester(CSHEH) Based on Smart Solar Panel and Concentrated Thermoelectric Generator. International Congress on Science and Engineering Research(ICSER). 2015. 